Pesquisa Florestal Brasileira $\begin{aligned} & \begin{array}{l}\text { Pesqian Journal of Forestry Research } \\ \text { Brazilian } \\ \text { http://pfb.cnpf.embrapa.br/pfb/ }\end{array} \\ & \text { ISSN: 1983-2605 (online) } \\ & \begin{array}{c}\text { Check for } \\ \text { updates }\end{array}\end{aligned}$

\title{
Nutrição e enraizamento adventício de plantas lenhosas
}

\author{
Fernanda Bortolanza Pereira ${ }^{1 *}$, Fabiana Schmidt Bandeira Peres ${ }^{1}$ \\ ${ }^{1}$ Universidade Estadual do Centro-Oeste, PR 153, Km 7, s/n, CEP 84500-000, Irati, PR, Brasil
}

*Autor correspondente:

fbp.engflorestal@gmail.com

Termos para indexação:

Rizogênese

Propagação

Estaquia

Index terms:

Root formation

Propagation

Cutting

Histórico do artigo:

Recebido em 11/02/2016

Aprovado em 15/07/2016

Publicado em 30/09/2016

doi: $10.4336 / 2016 . p f b .36 .87 .1146$

\begin{abstract}
Resumo - O sucesso da propagação vegetativa de genótipos comerciais via técnicas de estaquia está relacionado a diversos fatores, dentre os quais o estado nutricional das plantas matrizes e dos propágulos. O status nutricional determina a quantidade de carboidratos, auxinas e outros compostos do metabolismo essencial da planta para a iniciação e desenvolvimento da rizogênese. Cada nutriente possui na planta funções específicas essenciais, podendo atuar estrutural ou fisiologicamente. Contudo, apesar de se reconhecer a importância da nutrição mineral para o sucesso da propagação vegetativa de espécies lenhosas e sua relação com o enraizamento adventício, o papel de alguns elementos é ainda desconhecido. Pela complexidade bioquímica e fisiológica do processo de enraizamento adventício, há escassez de trabalhos buscando determinar o papel dos nutrientes no desenvolvimento adventício de raízes. A presente revisão bibliográfica pretende explorar o estado da arte sobre o efeito da nutrição mineral no enraizamento adventício de espécies lenhosas.
\end{abstract}

\section{Nutrition and adventitious rooting in woody plants}

\begin{abstract}
Vegetative propagation success of commercial genotypes via cutting techniques is related to several factors, including nutritional status of mother trees and of propagation material. The nutritional status determines the carbohydrate quantities, auxins and other compounds of plant essential metabolism for root initiation and development. Each nutrient has specific functions in plant, acting on plant structure or on plant physiology. Although the importance of mineral nutrition for success of woody plants vegetative propagation and its relation with adventitious rooting is recognized, the role of some mineral nutrients is still unknown. Due to biochemical and physiological complexity of adventitious rooting process, there are few researches to determine de role of nutrients on development of adventitious roots. This review intends to explore de state of the art about the effect of mineral nutrition on adventitious rooting of woody plants.
\end{abstract}

\section{Introdução}

O sucesso da eucaliptocultura no Brasil muito se deve ao desenvolvimento da propagação vegetativa de clones de alto valor comercial de Eucalyptus spp., pelo aprimorando dos processos silviculturais, que envolvem desde a produção de mudas de elevado padrão de qualidade até a otimização da colheita florestal. Somado a isto, observou-se um avanço muito rápido das técnicas de propagação vegetativa, especialmente no que toca a mini e microestaquia (Assis et al., 2004; Goulart et al., 2014).
Contudo, o sucesso da produção via estaquia depende de vários fatores intrínsecos à espécie, e até mesmo ao indivíduo que se está propagando, e aqueles referentes ao meio e ao manejo deste material vegetal. Dentre os diversos fatores que influenciam o sucesso da estaquia está o estado nutricional tanto das plantas doadoras de propágulos quanto dos propágulos a serem regenerados em novas plantas, uma vez que o status nutricional determina a quantidade de carboidratos, auxinas e outros compostos do metabolismo essenciais da planta para a iniciação e desenvolvimento da rizogênese (Cunha et al., 2009c). 
Embora seja reconhecida a importância dos nutrientes no processo de enraizamento adventício, estes ainda são relativamente pouco estudados em função da dificuldade em se determinar e esclarecer o papel de cada um durante a rizogênese, devido à complexidade bioquímica e fisiológica envolvida no processo (Malavasi, 1994; Cunha et al., 2009b, 2009c), o que limita a produção de mudas clonais de espécies florestais consideradas de difícil propagação (Brondani et al., 2014).

A presente revisão pretende explorar o estado da arte no que se refere aos conhecimentos sobre o efeito da nutrição mineral no enraizamento adventício de espécies lenhosas.

\section{Nutrição mineral e enraizamento adventício}

De forma sumarizada, o enraizamento adventício pode ser dividido em três fases básicas: i) indução - fase de modificações moleculares e bioquímicas anteriores às alterações anatômicas; ii) iniciação - multiplicação celular e estabelecimento dos meristemas, com surgimento dos primórdios radiculares; iii) expressão fase em que há emergência e crescimento dos primórdios radiculares formados previamente (Hartmann et al., 2011; Goulart et al., 2014). As raízes adventícias podem ser originadas em espécies lenhosas por formação direta de raízes, a partir de células próximas ao sistema vascular, ou indireta, quando a divisão celular origina tecidos chamados de calos antes da organização para iniciar o primórdio radicular (Hartmann et al., 2011).

O enraizamento adventício é controlado por um complexo conjunto de fatores (Zhao et al., 1991; Pawlick \& Welander, 1995; Assis et al., 2004) que incluem as condições ambientais, conteúdo endógeno e exógeno de hormônios e carboidratos, o estado nutricional e hídrico da planta, idade ontogenética e fisiológica do material, tipo de propágulo, incidência de luz, além da presença de determinados genes e enzimas, sendo necessário que todos estes fatores atuem ativamente para que ocorra indução das raízes adventícias (Zhao et al., 1991; Assis et al., 2004; Li et al., 2009; Pijut et al., 2011).

O efeito de topófise, ou seja, da posição dos ramos de coleta dentro da copa, também influencia no desempenho das estacas (Malavasi, 1994; Hartmann et al., 2011) em função de características anatômicas e hormonais, como a lignificação do tecido, desenvolvimento de esclerênquima e teores endógenos de auxinas (Wendling et al., 2014). No trabalho desenvolvido por Husen \& Pal (2007) com Tectona grandis (teca), os autores observaram que o maior comprimento e número de raízes foi obtido em estacas retiradas dos ramos mais altos, muito embora a maior porcentagem de enraizamento resultou das estacas obtidas na posição mediana da copa. Wendling et al. (2014) constataram que, para híbridos de Corymbia torelliana $\mathrm{x} C$. citriodora, o enraizamento e vigor foram maiores em estacas coletadas na porção apical das mudas, em função da menor lignificação do tecido e menor desenvolvimento de esclerênquima, que podem atuar como barreiras mecânicas ao desenvolvimento radicular.

A adubação mineral tem um efeito pronunciado tanto no tamanho quanto na morfologia dos sistemas radiculares de plantas, variando em função do nutriente, de sua concentração, do modo de aplicação e das condições do meio (Sattelmacher et al., 1993; Geiss et al, 2009; Li et al., 2009). A influência da nutrição mineral sobre o enraizamento pode ser atribuída à manutenção do vigor vegetativo da planta matriz ou, correlatamente, do estado nutricional equilibrado do próprio propágulo coletado quanto ao conteúdo de carboidratos, hormônios e outros compostos essenciais à indução radicular (Cunha et al., 2009c; Xavier et al., 2009; Pires et al., 2015), o que explica o fato de propágulos coletados de matrizes cultivadas em soluções nutritivas balanceadas enraizarem melhor do que os produzidos a partir de brotações coletadas diretamente em campo (Assis et al., 2004). Em minicepas de Araucaria angustifolia, a fertilização com solução mais concentrada de nutrientes levou à maior produção de miniestacas com melhor vigor radicial e hábito ortotrópico de crescimento (Pires et al., 2015). No entanto, essa resposta não se aplica para todas as espécies. Por exemplo, em sistema semi-hidropônico de condução das minicepas de ervamate (Ilex paraguariensis), Wendling et al. (2007) não observaram diferenças significativas entre as soluções nutritivas a $100 \%, 75 \%$ e $50 \%$ da concentração base ajustada para a espécie, de forma que os autores recomendam o uso da solução menos concentrada por questão de economia de recurso.

Entretanto, apesar de se reconhecer a importância da nutrição mineral tanto da planta fornecedora de propágulos quanto dos propágulos propriamente ditos e sua relação com o enraizamento adventício, o papel de alguns elementos são ainda desconhecidos (Cunha et al., 2009b; Geiss et al, 2009; Li et al., 2009).

Em geral, efeitos individuais de um único nutriente no enraizamento adventício não podem ser delineados claramente, em função da elevada correlação que há 
entre todos os elementos (Geiss et al., 2009; Trueman et al., 2013b), além destes efeitos serem dependentes da espécie e das condições ambientais em estudo (Geiss et al., 2009).

Trabalhos que visam elucidar o papel dos nutrientes no enraizamento adventício em sua maioria associam diferentes doses de determinado nutriente ao efeito observado nos propágulos, como nas pesquisas com Eucalyptus spp. conduzidas por Schwanbach et al. (2005), Carvalho Neto et al. (2011) e Rosa et al. (2009), ou ao efeito sobre a produtividade das matrizes, tal como apresentado por Souza et al. (2015) com Toona ciliata e Rocha et al. (2015) com híbrido de Eucalyptus ou, ainda, determinar a relação entre o conteúdo de determinado nutriente no tecido vegetal com o enraizamento, como apresentado por Ansari et al. (2004).

\section{Macronutrientes}

Os nutrientes requeridos em maior quantidade pelas plantas são: N, P. K, Ca, Mg e S, sendo denominados de macronutrientes (Malavolta, 2006).

$\mathrm{O} N$ é essencial para a planta por compor as proteínas e ácidos nucléicos, enzimas e coenzimas, vitaminas, hormônios, glico e lipoproteínas e pigmentos, como a clorofila e outros produtos secundários, além de participar da constituição de membranas, dos processos de absorção iônica, fotossíntese, respiração, multiplicação e diferenciação celular (Malavolta, 2006; Pallardy, 2008). No enraizamento adventício, sua influência também depende da relação entre este elemento e o conteúdo de carboidratos (relação $\mathrm{C} / \mathrm{N}$ ) e interações hormonais (Hartmann et al., 2011; Cunha et al., 2009b). De modo geral, manter uma relação $\mathrm{C} / \mathrm{N}$ elevada em matrizes doadoras de propágulos consiste numa condição ótima para o enraizamento de estacas lenhosas recalcitrantes (Hartmann et al., 2011).

Schwambach et al. (2005) caracterizaram a resposta de $E$. globulus ao enraizamento adventício in vitro frente a várias concentrações dos elementos nutrientes $\mathrm{N}$, $\mathrm{Ca}, \mathrm{P}, \mathrm{Fe}, \mathrm{Mn}, \mathrm{Zn}, \mathrm{B}$ e $\mathrm{Cu}$, com base no percentual de enraizamento, número de raízes, comprimento de raiz e tempo de enraizamento médio. Os autores observaram que a aplicação de $\mathrm{N}$ na forma de nitrato nas fases de indução e de iniciação influenciou o percentual de enraizamento, com um aumento significativo quando aplicados $18 \mathrm{mM}$ de nitrato; entretanto, doses de 120 $\mathrm{mM}$, além de reduzirem o enraizamento, provocaram clorose, indicando efeito tóxico desta concentração para as plantas em estudo.
Outro fato observado nos estudos envolvendo nutrição mineral associada ao enraizamento adventício é que a fonte de onde este nutriente é obtido também pode levar a efeitos diferenciados. Schwanbach et al. (2005) observaram que a fonte de $\mathrm{N}$ influenciou no comprimento e no número de raízes, sendo que o menor número de raízes e o menor tamanho foram observados quando as microestacas cresceram em meio com amônio como única fonte de $\mathrm{N}$ nas duas fases de enraizamento (indução e iniciação). Quando a fonte era apenas nitrato, em uma ou ambas as fases, o número de raízes foi similar ao tratamento controle (presença das duas fontes em ambas as fases), porém mais longas. $\mathrm{O}$ aumento na dose de nitrato levou ao encurtamento no comprimento radicular, sendo a dose de $18 \mathrm{mM}$ a que se mostrou mais responsiva, sem, contudo, alterar o percentual de enraizamento.

No estudo conduzido por Rosa et al. (2007) com E. dunnii, os autores observaram que diferentes formas de $\mathrm{N}$, amoniacal e/ou nitrato, na solução nutritiva do minijardim clonal também resultaram em variações do ponto de vista nutricional nas miniestacas. O uso de amônio, isolado ou acrescido de nitrato, levou a maiores valores de massa seca frente aos observados quando do uso de apenas nitrato como fonte de $\mathrm{N}$ na solução nutritiva.

Woodward et al. (2006), ao avaliarem o efeito de fontes de $\mathrm{N}$ e o tamponamento do meio para micropropagação de E. marginata, observaram que a maior produção de raízes ocorreu quando o meio continha $7,5 \mathrm{mM}$ de $\mathrm{N}$ na razão de $2 \mathrm{NO}_{3}^{-}$para $1 \mathrm{NH}_{4}^{+}$, tamponada com $10 \mathrm{mM}$ de ácido 2-(N-morfolino) etanosulfônico (MES).

Em relação às matrizes doadoras de propágulos, Carvalho Neto et al. (2011) avaliaram o efeito da fertirrigação em minicepas seminais com doses diferenciadas de N, P e K sobre a produção de miniestacas de E. urophylla, em sistema de hidroponia. Os autores verificaram que os teores de $\mathrm{N}, \mathrm{P}$ e $\mathrm{K}$ recomendáveis para a máxima produção de miniestaca por minicepa foram $50,7,5$ e $50 \mathrm{mg} \mathrm{L}^{-1}$, respectivamente. Somado a isto, os autores também observaram que o aumento na dose de $\mathrm{N}$ $\left(50,100,200\right.$ e $\left.400 \mathrm{mg} \mathrm{L}^{-1}\right)$ na forma de ureia reduziu o número de miniestacas por minicepa, o peso em matéria seca e o conteúdo de nutrientes na folha das miniestacas, enquanto não se verificou resposta às doses de $\mathrm{P}$ e $\mathrm{K}$. Rosa et al. (2009) avaliaram o efeito da fertirrigação com doses de nitrogênio em minicepas de E. dunnii e observaram que, ao contrário do efeito observado por 
Carvalho Neto et al. (2011) com E. urophylla, o aumento das doses de $\mathrm{N}\left(200,400\right.$ e $\left.600 \mathrm{mg} \mathrm{L}^{-1}\right)$ levou ao aumento na produtividade das minicepas, na sobrevivência das miniestacas bem como no vigor vegetativo das mudas formadas.

Ao avaliarem a produtividade de minicepas de cedroaustraliano (T. ciliata var. australis) em função do teor inicial de nutrientes em dois sistemas de minijardim multiclonal - canaletão e tubetes, Souza et al. (2015) também observaram correlações positivas entre a produtividade e o teor de nitrogênio nos tecidos vegetais.

Segundo Rocha et al. (2015), doses crescentes de $\mathrm{N}\left(0,80,160,240\right.$ e $\left.320 \mathrm{mg} \mathrm{L}^{-1}\right)$ em solução nutritiva de minicepas de clone híbrido de $E$. grandis x $E$. urophylla (I-224) tiveram efeito quadrático na produção de miniestacas, com máximo de produção com uma dose estimada de $129 \mathrm{mg} \mathrm{L}^{-1}$, enquanto o aumento da dose levou a um aumento linear no enraizamento das miniestacas. O tempo de enraizamento também sofreu influência da dose de $\mathrm{N}$ aplicada, onde $218 \mathrm{mg} \mathrm{L}^{-1}$ resultaria em menor tempo para surgimento das raízes na extremidade inferior do tubete, algo em torno de 19 dias.

Para matrizes de Pinus pinaster mantidas em casa de vegetação sob regime de adubação com doses alta (543,58 $\left.\mathrm{mg} \mathrm{L}^{-1}\right)$, média $\left(386,92 \mathrm{mg} \mathrm{L}^{-1}\right)$ e baixa $(309,69$ $\mathrm{mg} \mathrm{L}^{-1}$ ) de $\mathrm{N}$ em uma solução nutritiva base, MartínezAlonso et al. (2012) observaram que o aumento da dose de $\mathrm{N}$ elevou o número de miniestacas produzidas anualmente. Para a dose alta, o número de miniestacas enraizadas foi de $75,2 \%$ em comparação com os $66,7 \%$ obtidos com a menor dose de N. Esta diferença mantevese significativa ao longo do ano, exceto na primavera, época fisiologicamente mais favorável em que a dose mais baixa de $\mathrm{N}$ resultou em maior porcentagem de enraizamento. Rowe et al. (2002) observaram ainda que genótipos diferentes de $P$. taeda responderam de forma diferente às doses de $\mathrm{N}$ aplicadas, tendo uma das três procedências estudadas apresentado maior enraizamento na maior dose de $\mathrm{N}$ (70 $\left.\mathrm{mg} \mathrm{L}^{-1}\right)$, enquanto as demais apresentaram melhor performance na menor dose de $\mathrm{N}$ (10 $\left.\mathrm{mg} \mathrm{L}^{-1}\right)$.

O P participa da composição de carboidratos, fosfolipídios constituintes das membranas, coenzimas, nucleoproteínas e ácidos nucléicos, além de atuar nos processos vitais da planta em função do armazenamento e transferência de energia na forma de ATP (adenosinatrifosfato) (Malavolta, 2006; Pallardy, 2008). Sendo assim, é esperado que este macronutriente seja altamente requerido para os processos de diferenciação, divisão e multiplicação celular.

Ansari et al. (2004) avaliaram as porcentagens de brotação e enraizamento, número e tamanho de raízes, bem como o percentual de ionização do ácido indolacético (AIA), após o tratamento prévio de estacas lenhosas de Pongamia pinnata por mergulho basal em soluções salinas de $\mathrm{P}, \mathrm{S}, \mathrm{Mn}$ e $\mathrm{Cl}$. Os tratamentos consistiram na imersão por $24 \mathrm{~h}$ da base de cada estaca nas soluções salinas de 5,0 $\mathrm{mmol} \mathrm{L}^{-1}$ de $\mathrm{KMnO}_{4}$, 5,0 $\mathrm{mmol} \mathrm{L}^{-1}$ de $\mathrm{KCl}, 5,0 \mathrm{mmol} \mathrm{L}-1$ de $\mathrm{KH}_{2} \mathrm{PO}_{4}, 2,5$ mmol L-1 de $\mathrm{K}_{2} \mathrm{HPO}_{4}$ e $2,5 \mathrm{mmol} \mathrm{L}_{-1}$ de $\mathrm{K}_{2} \mathrm{SO}_{4}$. Foi observado que os sais de $\mathrm{P}$ e $\mathrm{S}$ tiveram influência positiva na indução e crescimento de raízes adventícias, com melhoria significativa em relação ao tratamento controle. Segundo os autores, esta influência positiva dos sais de $\mathrm{P}$ e $\mathrm{S}$ pode ser atribuída ao modo de ação destes elementos durante o enraizamento adventício, por serem nutrientes minerais essenciais aos processos vitais nas plantas, por participarem na interação com as auxinas, auxiliando o processo de indução radicular; ou por atuarem na aquisição de competência celular para o desenvolvimento de primórdios radiculares.

Quanto a ionização do AIA, a análise de regressão feita por Ansari et al. (2004) demonstrou correlação negativa com a brotação, enraizamento, número e tamanho de raízes. O baixo potencial de ionização observado pelos autores, em relação aos sais de $\mathrm{P}$ e $\mathrm{S}$ em comparação com os sais de $\mathrm{Cl}$ e $\mathrm{Mn}$, aparenta estimular a rizogênese adventícia e atuar na redistribuição lateral desta auxina, estimulando o crescimento lateral das raízes.

Souza et al. (2015), trabalhando com cedroaustraliano, observaram que os teores de fósforo nas miniestacas provenientes de minijardim em canaletão e de minijardim em tubetes foram diferentes, exceto aos 115 dias da poda apical em que estes foram semelhantes, e a produtividade das minicepas apresentou correlação positiva em relação à concentração de fósforo nos tecidos foliares.

O S é constituinte dos aminoácidos cisteína e metionina, de coenzimas, como a tiamina e a biotina, proteínas como a ferredoxinas e tioredoxinas, e sulfolipídios, sendo essencial para a atividade de membranas e síntese de proteínas (Malavolta, 2006; Pallardy, 2008). Cunha et al. (2009a, 2009c) observaram que níveis considerados na faixa entre deficiente e baixo foram suficientes para o enraizamento satisfatório das estacas de Eucalyptus spp., indicando que neste caso o 
processo de enraizamento adventício é pouco afetado pelo S.

O K apresenta papel ativador para mais de 50 enzimas, atua na regulação estomática e osmótica e na translocação de açúcares (Malavolta, 2006).

Paula et al. (2003) observaram interação entre as doses de $\mathrm{K}$ aplicadas às minicepas e à produção e sobrevivência de miniestacas de dois clones híbridos de E. grandis x E. urophylla, bem como na formação de calos e raízes. As doses crescentes de $\mathrm{K}$ levaram a um aumento na produção das miniestacas e na sobrevivência das mesmas. Contudo, cada material genético apresentou resposta diferenciada de incremento para doses de K, sugerindo a influência da constituição genética nas exigências nutricionais de cada indivíduo e a necessidade de se ajustar soluções nutritivas para cada material genético.Segundo os autores, o acréscimo de K teve efeitos opostos no enraizamento, sendo que em um dos clones houve inibição da diferenciação de calos em raízes e no outro ocorreu um aumento no enraizamento na ordem de $20 \%$. No material onde o $\mathrm{K}$ teve efeito inibitório, os autores verificaram que o aumento das doses de $\mathrm{K}$ levaram a um maior desenvolvimento de calos.

Schwanbach et al. (2005) observaram que variações nas doses de $\mathrm{K}(0,6,20,40$ e $80 \mathrm{mM})$ nas fases de indução e de formação de microestacas de $E$. globulus não apresentaram efeito sobre o processo de enraizamento. As doses em nível de deficiência ou elevadas tenderam a reduzir o comprimento e o número de raízes em comparação ao tratamento controle.

O Ca compõe estruturalmente compostos como pectato, carbonato, oxalato, fosfato, calmodulinas e anexinas; atua na regulação enzimática de ATPase, alfa amilase, fosfolipase, nucleases e poligalacturonase, bem como nos processos de funcionamento de membranas, relação com hormônios e transporte de auxina, abscisão e senescência, entre outros (Malavolta, 2006; Li et al.; 2009).

O Ca é um dos poucos elementos minerais que apresenta efeito mais pronunciado no processo de enraizamento (Bellamine et al., 1998; Schwambach et al.; 2005; Geiss et al., 2009), por atuar nos processos de divisão e elongação celular e como um mensageiro secundário na ação da auxina (Geiss et al., 2009).

Estudo in vitro conduzido por Bellamine et al. (1998) com estacas de Populus tremula x P. tremuloides demonstrou que a ausência de Ca no meio de crescimento durante a fase de expressão reduziu o enraizamento das estacas em $45 \%$. Além disso, a presença de EGTA, que forma quelatos com $\mathrm{Ca}$, e de cloreto de lantânio, bloqueador dos canais de $\mathrm{Ca}$, no meio de crescimento em que houve ou não a adição de $\mathrm{Ca}$, levou à inibição do enraizamento, suportando a hipótese de que o conteúdo de cálcio endógeno do propágulo implica positivamente no processo de enraizamento adventício.

Apesar disto, Cunha et al. (2009c) não observaram efeito do $\mathrm{Ca}$ sobre o enraizamento de estacas de Eucalyptus spp. Assis et al. (2004) apontam que em experimento envolvendo o crescimento in vitro de estacas de híbridos de $P$. tremula x $P$. tremuloides observou-se a inibição da formação de raízes na ausência de $\mathrm{Ca}$. A partir da experiência com miniestaquia de Eucalyptus spp., os mesmos autores afirmam que quando a concentração foliar de $\mathrm{Ca}$ é inferior a $0,7 \%$ o enraizamento é significativamente reduzido, especialmente nas épocas frias.

Schwanbach et al. (2005) observaram que para microestaquia de E. globulus o aumento na concentração de Ca levou ao aumento no número de raízes adventícias das microestacas, quando aplicado nas duas fases (indução e formação). Teores elevados de Ca durante a fase de indução tiveram efeito mais pronunciado do que na fase de formação. Esta "fase-dependência" foi comprovada pela aplicação de $15 \mathrm{mM}$ de $\mathrm{Ca}$ separadamente nas fases de indução e de formação, o que, segundo os autores, induziu ao aumento no número de raízes quando o $\mathrm{Ca}$ foi aplicado apenas na fase de indução.

\section{Micronutrientes}

O B é um micronutriente de grande importância para as plantas por atuar, dentre outras funções não totalmente esclarecidas, na formação de diois, na biossíntese de lignina, na indução de raízes adventícias e germinação do grão de pólen, no processo de fotossíntese, metabolismo e transporte de carboidratos, manutenção da integridade de paredes e membranas celulares, entre outras (Malavolta, 2006). O B desempenha funções também no alongamento celular, síntese de ácidos nucleicos, respostas hormonais e funcionamento de membranas (Taiz \& Zeiger, 2004; Li et al.; 2009) e, portanto, consiste num importante componente da solução nutritiva visando à produção de brotos com qualidade e em quantidade (Brondani et al., 2012).

No enraizamento adventício, o B pode ser elencado como essencial por sua atuação na manutenção da 
atividade meristemática, possivelmente associado à síntese de uracila, que é base nitrogenada componente do RNA, afetando desta forma a síntese proteica essencial aos processos meristemáticos (Castro et al., 2012). Além disso, o B pode otimizar a atividade da enzima oxidase sobre AIA, regulando os níveis endógenos desta auxina (Hartmann et al., 2011).

Alterações nas concentrações de $\mathrm{B}$, bem como de $\mathrm{Cu}$, não afetaram o enraizamento de microestacas de $E$. globulus (Schwanbach et al., 2005). Para miniestacas de E. cloeziana (Trueman et al., 2013b), E. dunnii e C. citriodora (Trueman et al. 2013a) as concentrações mais altas de $\mathrm{B}$ no tecido foliar se correlacionaram positivamente com o enraizamento adventício.

No crescimento de mudas clonais de I. paraguariensis, Benedetti et al. (2014) observaram que doses próximas a 5,0 $\mathrm{mg} \mathrm{L}^{-1}$ de B na solução nutritiva resultaram em engrossamento das raízes, que pode ter sido a causa da redução do crescimento das mudas em doses elevadas do micronutriente, por apresentarem menor eficiência na absorção de nutrientes e água. Contudo, os autores também observaram que a dose que apresentou melhores resultados com mudas clonais de erva-mate foi de $3,0 \mathrm{mg} \mathrm{L}^{-1}$, superior à recomendada na literatura que é de $0,5 \mathrm{mg} \mathrm{L}^{-1}$, ressaltando-se desta maneira a necessidade de estudos sobre nutrição para as espécies arbóreas passíveis de clonagem.

Brondani et al. (2012) avaliaram a sobrevivência de minicepas de clones de E. benthamii, a produção de miniestacas e o teor foliar nutricional e de carboidratos em relação a diferentes concentrações de $\mathrm{Zn}$ e B entre coletas sucessivas. Soluções nutritivas contendo 1,0 e 2,0 $\mathrm{mg} \mathrm{L}^{-1}$ de $\mathrm{Zn}$ e B favoreceram a sobrevivência das minicepas, a produção de miniestacas e o acúmulo de macro e micronutrientes. $\mathrm{O}$ aumento das doses de $\mathrm{Zn}$ e $\mathrm{B}$ levou à redução do teor de carboidratos na planta. Estas mesmas soluções nutritivas com 1,0 e 2,0 $\mathrm{mg} \mathrm{L}^{-1}$ de $\mathrm{Zn}$ e B associadas à aplicação de AIB em estacas de E. benthamii resultaram em acréscimo no enraizamento adventício (Brondani et al., 2014), atribuindo-se este efeito à demanda de $\mathrm{Zn}$ na síntese de triptofano, favorecendo a síntese de auxinas endógenas promotoras da rizogênese na estaca.

$\mathrm{OZn}$ atua indiretamente no enraizamento, promovendo aumento do conteúdo de auxinas pelo aumento das reservas de triptofano, que é o precursor natural do AIA (Hartmann et al., 2011; Cunha et al., 2009c). Cunha et al. (2009c) não verificaram efeito positivo da nutrição das minicepas de Eucalyptus spp. com Zn sobre o enraizamento de estacas. Entretanto, Cunha et al. (2009a) observaram que o $\mathrm{Zn}$ influenciou positivamente o enraizamento de miniestacas de clones de Eucalyptus spp., mostrando comportamento diferenciado para os diferentes materiais genéticos testados.

Schwambach et al. (2005) observaram que, assim como o $\mathrm{N}$ na forma de nitrato, o $\mathrm{Zn}$ aplicado em $E$. globulus nas fases de indução e formação de raízes adventícias in vitro influenciou significativamente no percentual de enraizamento. Os autores observaram que doses de $30 \mu \mathrm{M}$ de $\mathrm{Zn}$ levaram ao enraizamento de $100 \%$ dos propágulos, enquanto o tratamento com ausência de $\mathrm{Zn}$ teve um enraizamento na ordem de $75 \%$, não diferindo do tratamento controle (concentração de $9 \mu \mathrm{M}$ ). Os autores ainda observaram que doses de $60 \mu \mathrm{M}$ de $\mathrm{Zn}$ no meio de indução e de formação resultaram em um maior número de raízes. Contudo, o Zn não teve influência sobre o comprimento de raízes.

O Mn deve ser utilizado em doses mínimas, em função do efeito inibitório sobre o enraizamento (Assis et al., 2004), que pode ser atribuído ao fato deste elemento atuar como ativador do sistema enzimático de oxidação de auxinas (Hartmann et al., 2011). Ansari et al. (2004), observaram que a imersão das estacas de $P$. pinnata em solução de $5,0 \mathrm{mmol} \mathrm{L}^{-1}$ de $\mathrm{KMnO}_{4}$ reduziu o enraizamento adventício, atribuído a um efeito fitotóxico, enquanto o uso de sal de cloro $(\mathrm{KCl})$ não apresentou diferenças significativas. Além disso, o maior valor de ionização do AIA em função do uso de sais de $\mathrm{Cl}$ e de $\mathrm{Mn}$ inibiu a rizogênese.

Em E. globulus, a deficiência de Mn na fase de indução de raízes levou ao aumento no comprimento de raízes, quando em comparação com a deficiência de $\mathrm{Mn}$ na fase de formação, sem que alterações nos teores deste micronutriente afetassem o número de raízes formadas (Schwanbach et al., 2005).

$\mathrm{O}$ Fe possui função estrutural, formando quelatos e fitoferretina. Atua como constituinte de proteínas, como a ferredoxina e peroxidases, ou na ativação de enzimas e participa de processos metabólicos, como a fotossíntese, respiração, fixação do N, assimilação do $\mathrm{N}$ e do S, síntese de lignina e suberina e no metabolismo de auxinas (Malavolta, 2006). Cunha et al. (2009c), avaliando o efeito da nutrição mineral das minicepas no enraizamento das miniestacas de Eucalyptus spp., observaram que o $\mathrm{Fe}$ apresentou efeito positivo sobre o desenvolvimento de raízes adventícias, sendo necessário, entretanto, 
estudos elucidativos do papel deste nutriente sobre esse processo. Schwanbach et al. (2005) observaram em microestaquia de E. globulus, que a deficiência de $\mathrm{Fe}$ na fase de indução acarretou aumento significativo no comprimento de raízes das estacas quando comparado ao tratamento controle. Na fase de formação, esses autores observaram que o efeito da variação no teor de Fe se fez mais evidente sobre o enraizamento das estacas, pois este elemento atua na biossíntese de peroxidases envolvidas no catabolismo de auxinas, afetando desta forma a formação e lignificação das paredes celulares, com acúmulo de compostos fenólicos na rizoderme e escurecimento das porções basais.

Para minicepas de cedro-australiano, Souza et al. (2015) observaram que o $\mathrm{Cu}, \mathrm{Fe}, \mathrm{Mn}$ e $\mathrm{Zn}$ resultaram em correlações positivas com a produtividade de miniestacas, de forma que a reposição regular destes nutrientes pode favorecer, segundo os autores, o aumento da produtividade de minijardins multiclonais.

\section{Considerações finais}

Há na literatura escassez de informação sobre os efeitos da nutrição mineral no enraizamento adventício, principalmente sobre espécies lenhosas, o que abre um campo amplo para estudos fisiológicos vinculados a este processo.

Os efeitos dos nutrientes e as faixas favoráveis ao enraizamento em cada etapa do processo de rizogênese devem ser estudados para casa espécie e ajustados para cada ocasião e material genético, em virtude das variações entre indivíduos, espécies e procedências.

\section{Referências}

Ansari, S. A. et al. Inorganic salts influence IAA ionization and adventitious rhizogenesis in Pongamia pinnata. Journal of Plant Phisiology, v. 161, p. 117-120, 2004. DOI: 10.1078/0176-161701078.

Assis, T. F. et al. Current techniques and prospects for the clonal propagation of hardwood with emphasis on Eucalyptus. In: Fort, P. $\mathrm{O}$. et al. (Ed.). Proceedings of plantation forest biotechnology for the 21st century. New Delhi: Research Signpost, 2004. p. 303-333.

Bellamine, J. et al. Confirmation of the role of auxin and calcium in the late phases of adventitious root formation. Plant Growth Regulation, v. 26, p. 191-194, 1998. DOI: 10.1023/A:1006182801823.
Benedetti, E. L. et al. Boro no crescimento de mudas de erva-mate em solução nutritiva. In: CONGRESO SUDAMERICANO DE YERBA MATE, 6., SIMPOSIO INTERNACIONAL DE YERBA MATE Y SALUD, 2., 2014, Montevideo. Memorias... [S.1]: Grupo Interdisciplinario de Yerba Mate y Salud, 2014.

Brondani, G. E. et al. Avaliação morfológica e produção de minijardim clonal de Eucalyptus benthamii em relação a Zn e B. Pesquisa Florestal Brasileira, v. 32, n. 70, p. 151-164, 2012. DOI: 10.4336/2012.pfb.32.70.35.

Brondani, G. E. et al. Miniestaquia de Eucalyptus benthamii: efeito do genótipo, AIB, zinco, boro e coletas de brotações. Cerne, v. 20, n. 1, p. 147-156, 2014. DOI: 10.1590/S0104-77602014000100018.

Carvalho Neto, J. P. et al. Effect of NPK fertilization on production and leaf nutrient contente of Eucalyptus minicuttings in nutriente solution. Revista Brasileira de Ciência do Solo, v. 35, p. 249-254, 2011. DOI: $10.1590 / \mathrm{S} 0100-06832011000100023$.

Castro, P. R. C. et al. Nutrição vegetal e biorregulação no desenvolvimento das plantas. Informações Agronômicas, n. 139, 2012.

Cunha, A. C. M. C. M. et al. Influência do estado nutricional de minicepas no enraizamento de miniestacas de eucalipto. Revista Árvore, v. 33, n. 4, p. 607-615, 2009a. DOI: 1 0.1590/S010067622009000400003.

Cunha, A. C. M. C. M. et al. Papel da nutrição mineral na formação de raízes adventícias em plantas lenhosas. Pesquisa Florestal Brasileira, n. 58, p. 33-47, 2009b. DOI: 10.1590/S010067622009000400003 .

Cunha, A. C. M. C. M. et al. Relação do estado nutricional de minicepas com o enraizamento de miniestacas de eucalipto. Revista Brasileira de Ciência do Solo, v. 33, p. 591-599, 2009c. DOI: 10.1590/S0100-06832009000300012.

Geiss, G. et al. Adventitious root formation: new inssights and perspectives. In: Beeckman, T. (Ed.). Annual plant reviews: root development. New York: John Wiley \& Sons, 2009. v. 37. p. 127-156.

Goulart, P. B. et al. Morfoanatomia da rizogênese adventícia em miniestaca de Eucalyptus grandis x Eucalyptus urophylla. Ciência Florestal, v. 24, n. 3, p. 521-532, 2014. DOI: 10.5902/1980509815721.

Hartmann, H. T. et al. Plant propagation: principles and practices. 8th ed. New Jersey: Prentice-Hall, 2011. 915 p.

Husen, A. \& Pal, M. Effect of branch position and auxin treatment on clonal propagation of Tectona grandis Linn. f. New Forests, v. 34, p. 223-233, 2007. DOI: 10.1007/s11056-007-9050-y.

$\mathrm{Li}, \mathrm{S}$. W. et al. Mediators, genes and signaling in adventitious rooting. The Botanical Review, v. 75, n. 2, p. 230-247, 2009. DOI: 10.1007/ s12229-009-9029-9.

Malavasi, U. C. Macropropagação vegetativa em coníferas: perspectivas biológicas e operacionais. Floresta e Ambiente, v. 1, p. 131-135, 1994.

Malavolta, E. Manual de nutrição mineral de plantas. São Paulo: Agronômica Ceres, 2006. 638 p. 
Martínez-Alonso, C. et al. Optimization of seasonality and mother plant nutrition for vegetative propagation of Pinus pinaster Ait. New Forests, v. 43, p. 651-663, 2012. DOI: 10.1007/s11056-012-9333-9.

Pallardy, S. G. Physiology of woody plants. 3rd ed. Burlington: Academic Press, 2008. 464 p.

Paula, T. A. et al. Efeito do potássio na produção e enraizamento de miniestacas de eucalipto na presença e ausência de AIB. In: CONGRESSO BRASILEIRO DE CIÊNCIA DO SOLO, 29., 2003, Ribeirão Preto. Solo: alicerce dos sistemas de produção. Botucatu: UNESP; Ribeirão Preto: SBCS, 2003. CD-ROM.

Pawlick, N. \& Welander, M. Influence of carbohydrate source, auxin concentration and time of exposure on adventitious rooting of the apple rootstock Jork 9. Plant Science, v. 109, p. 167-176, 1995. DOI: 10.1016/0168-9452(95)04074-5.

Pijut, P. M. et al. Promotion of adventitious root formation of difficultto-root hardwood tree species. Horticultural Reviews, v. 38, p. 213-251, 2011. DOI: 10.1002/9780470872376.ch6.

Pires, P. et al. Sazonalidade e soluções nutritivas na miniestaquia de Araucaria angustifolia (Bertol.) Kuntze. Revista Árvore, v. 39, n. 2, p. 283-293, 2015. DOI: 10.1590/0100-67622015000200008.

Rocha, J. H. T. et al. Produtividade do minijardim e qualidade de miniestacas de um clone de híbrido de Eucalyptus grandis $\mathrm{x}$ Eucalyptus urophylla (I-224) em função de doses de nitrogênio. Ciência Florestal, v. 25, n. 2, p. 273-279, 2015. DOI: 10.5902/1980509818411.

Rosa, L. S. et al. Efeito da dose de nitrogênio e de formulações de substratos na miniestaquia de Eucalyptus dunnii Maiden. Revista Árvore, v. 33, n. 6, p. 1025-1035, 2009. DOI: 10.1590/S010067622009000600005.

Rosa, L. S. et al. Efeito do nitrogênio no estão nutricional e na produção de biomassa em minicepas de Eucalyptus dunnii Maiden. Cerne, v. 13, p. 17-22, 2007.

Rowe, D. B. et al. Nitrogen nutrition of hedged stock plants of Loblolly Pine. II. Influence of carbohydrate and nitrogen status on adventitious rooting of stem cuttings. New Forests, v. 24, p. 53-65, 2002. DOI: 10.1023/A:1020555013964.
Sattelmacher, B. et al. Interaction between root growth and mineral nutrition. Environmental and Experimental Botany, v. 33, n. 1, p. $63-79,1993$. DOI: 10.1016/0098-8472(93)90056-L.

Schwanbach, J. et al. Mineral nutrition and adventitious rooting in microcuttings of Eucalyptus globulus. Tree Physiology, v. 25, p. 487-494, 2005. DOI: 10.1093/treephys/25.4.487.

Souza, J. S. et al. Produtividade de minicepas de cedro-australiano em função do teor inicial de nutrientes. Floresta, v. 45, n. 3, p. $617-$ 624, 2015. DOI: 10.5380/rf.v45i3.36529.

Taiz, L. \& Zeiger, E. Fisiologia vegetal. Porto Alegre: Artmed, 2004. 722 p.

Trueman, S. J. et al. Production of cuttings in response to stock plant temperature in the subtropical eucalypts, Corymbia citriodora and Eucalyptus dunnii. New Forests, v. 44, p. 265-279, 2013a. DOI: 10.1007/s11056-012-9315-y.

Trueman, S. J. et al. Production of Eucalyptus cloeziana cuttings in response to stock plant temperature. Journal of Tropical Forest Science, v. 25, n. 1, p. 60-69, 2013b

Wendling, I. et al. Produção e sobrevivência de miniestacas e minicepas de erva-mate cultivadas em sistema semi-hidropônico. Pesquisa Agropecuária Brasileira, v. 42, n. 2, p. 289-292, 2007. DOI: $10.1590 / \mathrm{S} 0100-204 X 2007000200019$.

Wendling, I. et al. Topophysis in Corymbia torelliana x C. citriodora seedlings: adventitious rooting capacity, stem anatomy, and auxin and abscisic acid concentrations. New Forests, v. 46, p. 107-120, 2014. DOI: 10.1007/s11056-014-9451-7.

Woodward, A. J. et al. The effect of nitrogen source and concentration, medium $\mathrm{pH}$ and buffering on in vitro shoot growth and rooting in Eucalyptus marginata. Scientia Horticulturae, v. 110, p. 208-213, 2006. DOI: $10.1016 /$ j.scienta.2006.07.005.

Xavier, A. et al. Silvicultura clonal: princípios e técnicas. Viçosa, MG: Ed. da UFV, 2009. 272 p.

Zhao, Z. R. et al. Promotive effect of potassium on adventitious root formations in some plants. Plant Science, v. 79, p. 47-50, 1991. DOI: 10.1016/0168-9452(91)90067-I. 